\title{
Quantifying the impact of data sharing on variant classification
}

\author{
James Casaletto ${ }^{1}$, Melissa Cline ${ }^{1}$, and Brian Shirts ${ }^{2}$ \\ ${ }^{1} \mathrm{UCSC}$ \\ ${ }^{2}$ University of Washington School of Medicine
}

September 25, 2021

\begin{abstract}
Many genomic variants are currently classified, but many more are extremely rare, have minimal associated patient data, and are classified as variants uncertain significance (VUS). Accumulating patient data such as family history and de novo status can help classify variants. Understanding potential timelines for data accumulation and variant classification can inform reporting, diagnosis, and treatment decisions. We modeled future clinical data observations with different strategies for sharing and aggregating clinical evidence for variants across multiple sequencing centers over time. Models illustrate how long it takes for variants to be classified when evidence is or is not shared between clinical laboratories and compared to when only variant interpretations are shared. When sequencing centers share evidence the probability of classifying a one in 100,000 pathogenic variant increases from less than $25 \%$ to nearly $80 \%$ after one year and to nearly $100 \%$ with 5 years of observations. Extremely rare variants have a low likelihood of classification using clinical data even with optimal data sharing. Sharing clinical evidence between laboratories will lead to faster and more certain classifications. Modeling can effectively illustrate the likelihood of variant classification under current classification frameworks and may help define realistic provider and patient expectations.
\end{abstract}

\section{Hosted file}

main.docx available at https://authorea.com/users/437060/articles/538963-quantifying-theimpact-of-data-sharing-on-variant-classification
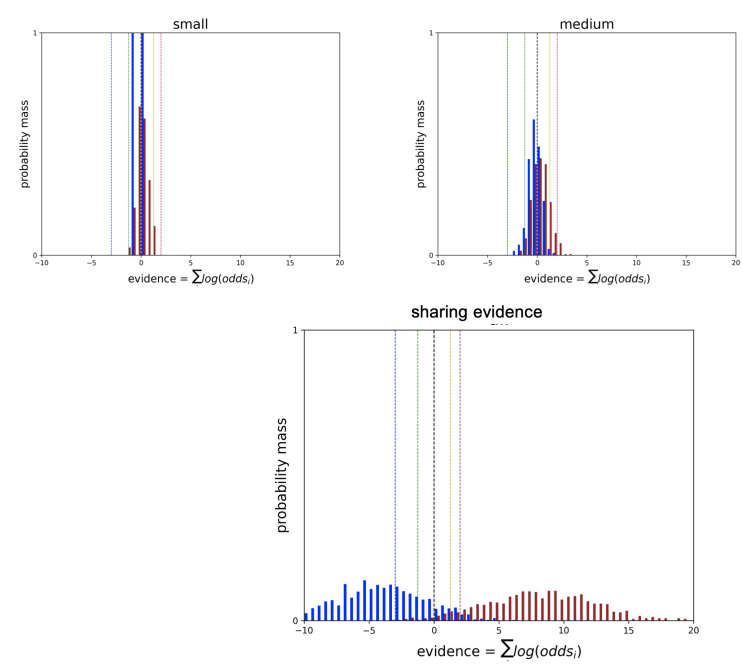
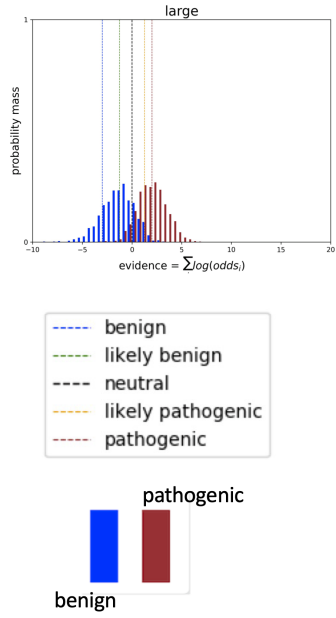

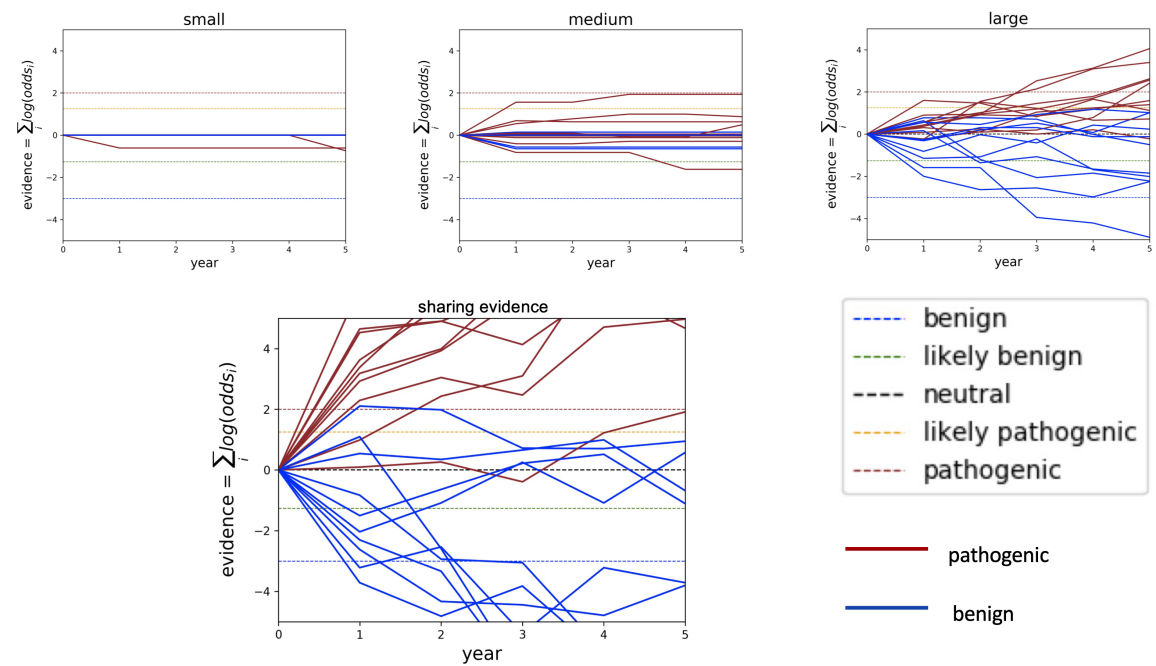

pathogenic

pathogenic

benign
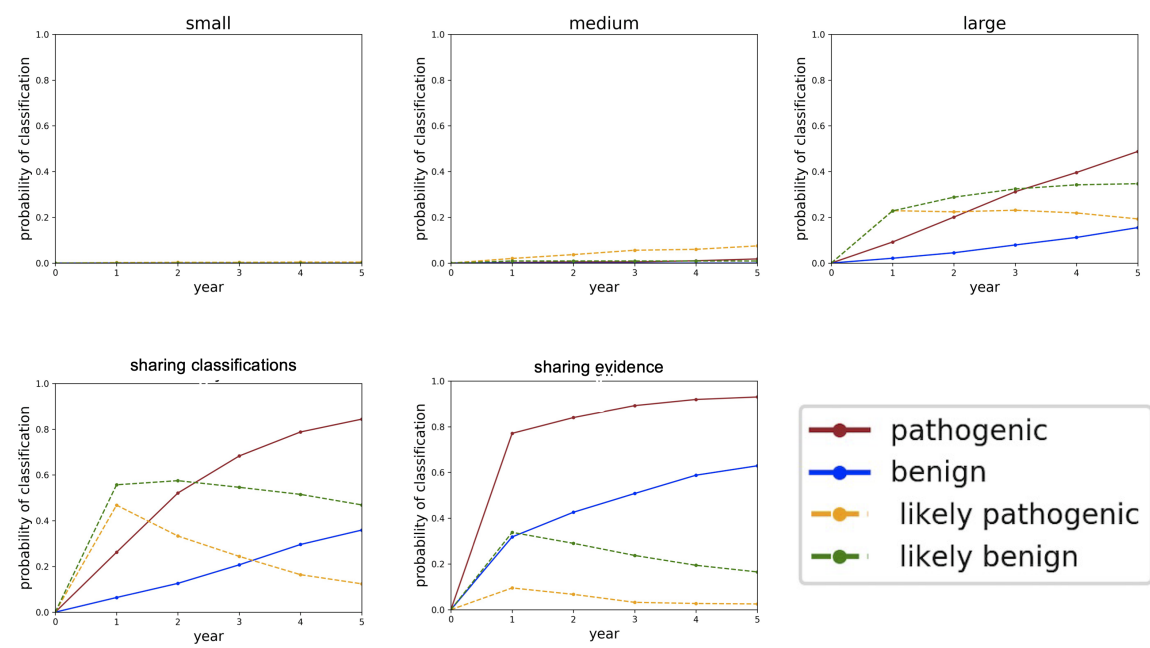

$\because$ pathogenic

$\longrightarrow$ benign

-o- likely pathogenic

-๑ likely benign

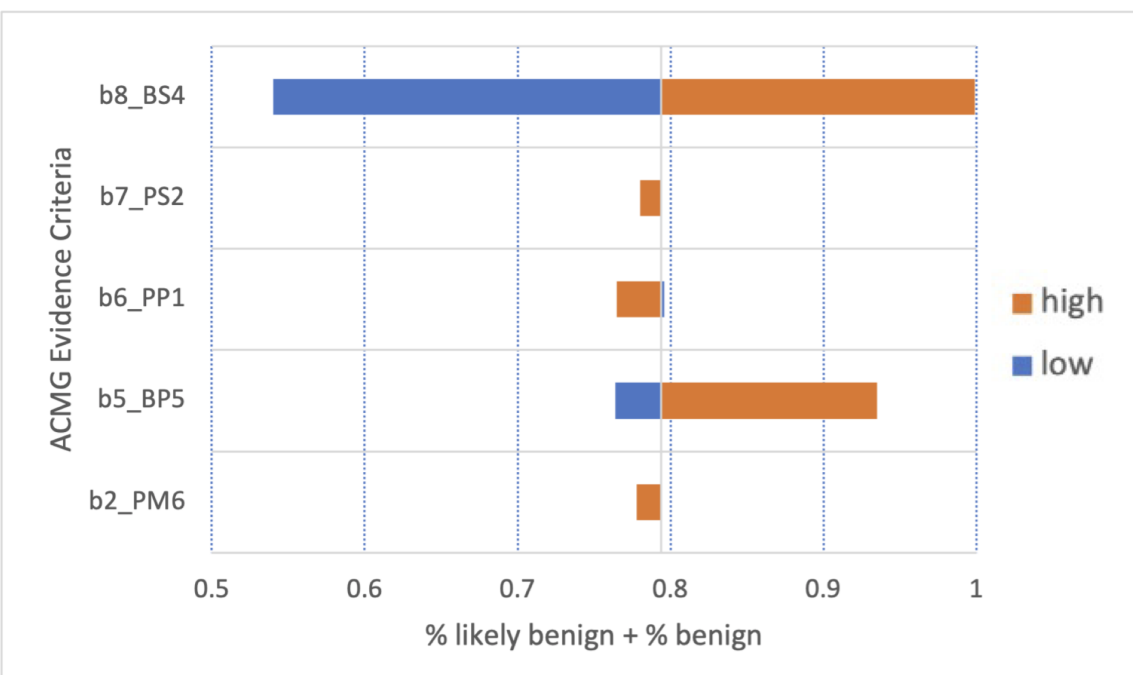




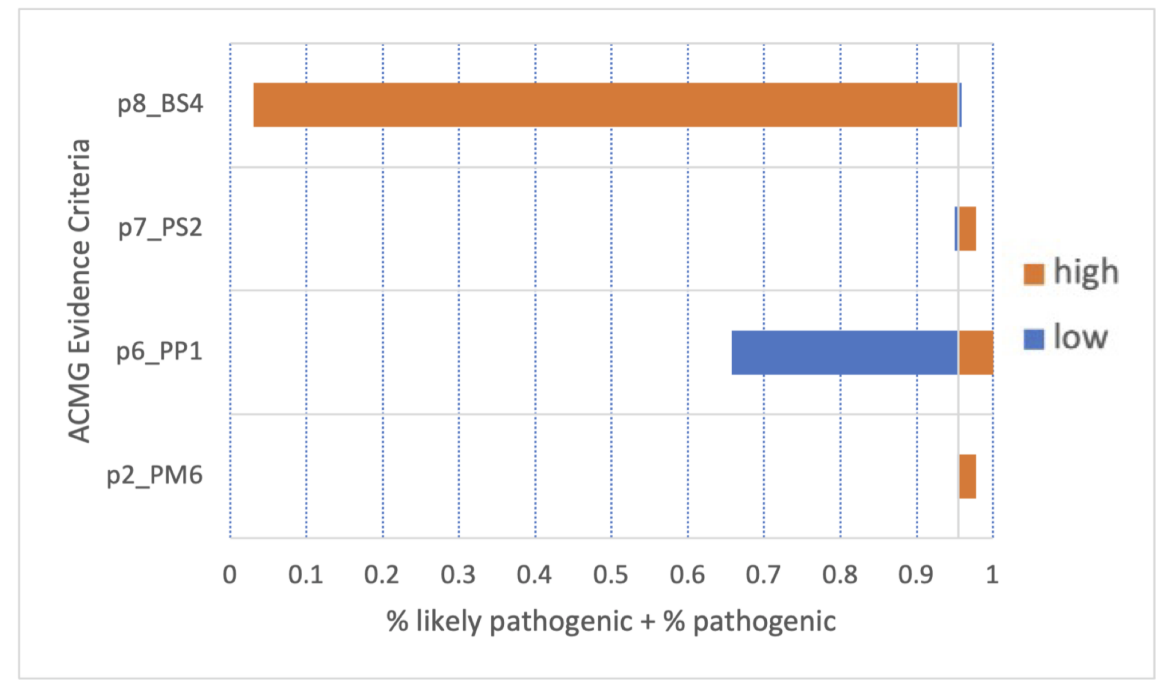

\section{Hosted file}

table_1.docx available at https://authorea.com/users/437060/articles/538963-quantifying-theimpact-of-data-sharing-on-variant-classification

\section{Hosted file}

table_2.docx available at https://authorea.com/users/437060/articles/538963-quantifying-theimpact-of-data-sharing-on-variant-classification

\section{Hosted file}

table_3.docx available at https://authorea.com/users/437060/articles/538963-quantifying-theimpact-of-data-sharing-on-variant-classification

\section{Hosted file}

table_4.docx available at https://authorea.com/users/437060/articles/538963-quantifying-theimpact-of-data-sharing-on-variant-classification 